\title{
For Critically Ill Patients, Is High-Flow Nasal Cannula Oxygen Delivery a Suitable Alternative to Mechanical Ventilation?
}

The purpose of respiratory support is to maintain adequate ventilation and oxygenation. Consequently, ensuring adequate alveolar ventilation is essential for expelling carbon dioxide produced in the human body. Currently, during invasive or noninvasive ventilatory support, minute ventilation is manipulated to ensure adequate alveolar ventilation. For patients with COPD exacerbations, noninvasive ventilation (NIV) has become the preferred primary modality for respiratory support because it both enhances inspiratory tidal volume and maintains adequate alveolar ventilation. Because of poor mask tolerance, however, NIV is sometimes inapplicable.

High-flow nasal cannula (HFNC) oxygen delivery has been gaining attention as an alternative means of respiratory support for critically ill patients. In the literature, this technique has also been called mini-CPAP, transnasal insufflation, nasal high flow, nasal high-flow ventilation, high-flow therapy, and high-flow nasal cannula oxygen therapy. Here, the term HFNC is used. The apparatus comprises an air-oxygen blender, an active heated humidifier, a single heated circuit, and a nasal cannula. The $\mathrm{F}_{\mathrm{IO}_{2}}$ is set in the air-oxygen blender from 0.21 to 1.0 with flows of up to $60 \mathrm{~L} / \mathrm{min}$. The gas is heated and humidified with the active humidifier and delivered through the heated circuit. Another big difference between NIV and HFNC is the interface. Although interfaces for NIV increase anatomical dead space, HFNC actually decreases dead space. Because neither inspiratory push nor expiratory pull is effective in such an open circuit, HFNC cannot actively enhance tidal volume. Even so, it helps patients with COPD mainly by decreasing anatomical dead space and improving alveolar ventilation.

In clinical trials with subjects with $\mathrm{COPD},{ }^{1}$ response to HFNC has been varied. For some subjects, it has been shown to reduce breathing frequency and, in some cases, to decrease $\mathrm{P}_{\mathrm{aCO}}$. Tested using an unloaded bicycle ergometer, compared with spontaneous breathing, ${ }^{2}$ HFNC has also increased the exercise capacity of some subjects, who show improved oxygenation. HFNC has proved to be an innovative and unique therapy for some types of hypercapnic respiratory failure.

Maintaining adequate oxygenation depends on properly managing $\mathrm{F}_{\mathrm{IO}_{2}}$ and PEEP. For hypoxemic patients, provision of supplemental oxygen has long been the frontline therapy. Oxygen is generally provided via a face mask or nasal cannula, with oxygen delivery limited to no more than $15 \mathrm{~L} / \mathrm{min}$. Using conventional methods, when there are large differences between patient inspiratory flow and delivered flow, $\mathrm{F}_{\mathrm{IO}_{2}}$ values are difficult to control and are usually lower than expected. However, HFNC literally delivers high flow, and actual $\mathrm{F}_{\mathrm{IO}_{2}}$ values are usually close to delivered $\mathrm{F}_{\mathrm{IO}_{2}} \cdot{ }^{3}$

\section{See the Original Study on Page 162}

Because high flow through a nasal cannula meets resistance from patient expiration, pressure in the pharynx increases. The cannula is part of an open system; therefore, pharyngeal pressure may not be high enough. Differences in positive pharyngeal pressure depend on gender, body mass index, mouth closing/opening, and flow during HFNC therapy. With the mouth open, pressure of $<3 \mathrm{~cm} \mathrm{H}_{2} \mathrm{O}$ has been reported, even with flow as high as $60 \mathrm{~L} / \mathrm{min}$. Under some conditions, when delivered gas flow is increased above $30 \mathrm{~L} / \mathrm{min}$, there is an almost linear response in mean upper-airway pressure: at $30 \mathrm{~L} / \mathrm{min}$, the mean upper-airway pressure approaches $3 \mathrm{~cm} \mathrm{H}_{2} \mathrm{O}$; at $40 \mathrm{~L} / \mathrm{min}$, it is $\sim 4 \mathrm{~cm} \mathrm{H}_{2} \mathrm{O}$; and at $50 \mathrm{~L} / \mathrm{min}$, it is $\sim 5 \mathrm{~cm} \mathrm{H}_{2} \mathrm{O}$. End-expiratory lung volume has been evaluated with electrical lung impedance tomography: it was greater with HFNC than with low-flow oxygen therapy. ${ }^{4}$

For patients with hypoxemic respiratory failure, how well does cannula delivery work in maintaining stable $\mathrm{F}_{\mathrm{IO}_{2}}$ and positive pharyngeal pressure? From the reported physiological effects of HFNC, although it has been effective for mild-to-moderate hypoxemic respiratory failure, ${ }^{5}$ it has not been recommended for severe hypoxemic respiratory failure because it is not possible to ensure sufficient positive pharyngeal pressure. Sztrymf et $\mathrm{al}^{6}$ evaluated HFNC in subjects with mild-to-moderate respiratory failure in a cardiothoracic care unit: HFNC treatment was successful for $26(68 \%)$ of the 38 subjects who received it. In another cardiothoracic ICU, Parke et $\mathrm{al}^{7}$ randomly assigned subjects with mild-to-moderate respiratory failure to HFNC or face mask delivery. Only $10 \%$ of the HFNC group needed NIV, whereas $44 \%$ of the face mask group required escalated therapeutic ventilation. Maggiore et $\mathrm{al}^{8}$ randomly assigned subjects after extubation to HFNC or air-entrain- 
ment mask. HFNC resulted in better oxygenation and a lower re-intubation rate. Even though we lack evidence from large randomized controlled trials (RCTs), the results from these studies suggest that innovative HFNC is an effective therapy for mild-to-moderate hypoxemic respiratory failure.

There have been few reports of HFNC use in severe acute respiratory failure. Rello et $\mathrm{al}^{9}$ applied HFNC during acute hypoxemic respiratory failure attributable to influenza A/H1N1virus. Five of the 25 subjects in this study received conventional oxygen administration. For the remaining 20 subjects, all of whom initially received supplemental oxygen at flows of $>9 \mathrm{~L} / \mathrm{min}$, it was not possible to maintain $\mathrm{S}_{\mathrm{pO}_{2}}$ above $92 \%$. HFNC was effective for 9 of the 20 subjects, who thus avoided intubation, which the remaining 11 subjects subsequently required. These results suggest that it could be initially worthwhile trying HFNC for patients with acute respiratory infection syndrome. Innovative HFNC may well be an effective modality for early treatment of adults with severe acute respiratory failure. Of course, further study is needed to establish efficacies and indicators for patients in this category, and we eagerly await the results of both the FLORALI (High Flow Oxygen Therapy for Resuscitation of Patients with Acute Lung Injury) study, which has completed subject enrollment, ${ }^{10}$ and the OPERA trial, which is evaluating how well HFNC prevents postextubation hypoxemia after abdominal surgery. ${ }^{11}$ The results of these RCTs will provide the kind of rigorous evidence we need to confidently guide clinical choices.

Even so, the results of large RCTs are not always as useful as we might anticipate. Single-center studies may also help us toward great improvements in practice. Close observation can provide well-founded useful conclusions: in this issue of Respiratory CARE, Messika et al ${ }^{12}$ report on the effectiveness of HFNC for subjects with ARDS, finding it effective for 26 of 45 subjects. Despite its limitations of being an observational study, and despite leaving open issues such as indications for HFNC, timing for start of HFNC, and criteria for escalating treatment beyond HFNC, the study suggests that innovative HFNC therapy is a promising modality for early treatment of adults with

Dr Nishimura has disclosed no conflicts of interest.

Correspondence: Masaji Nishimura MD PhD, Emergency and Critical Care Medicine, Tokushima University Graduate School, 3-18-15 Kuramoto, Tokushima 770-8503, Japan. E-mail: nmasaji@tokushima-u.ac.jp.

DOI: $10.4187 /$ respcare.03871 severe acute respiratory failure. It is time to reconsider our reliance on huge RCTs to provide conclusive evidence of the suitability of new treatments for each type of patient.

Masaji Nishimura MD PhD Emergency and Critical Care Medicine Tokushima University Graduate School Tokushima, Japan

\section{REFERENCES}

1. Bräunlich J, Beyer D, Mai D, Hammerschmidt S, Seyfarth HJ, Wirtz $\mathrm{H}$. Effects of nasal high flow on ventilation in volunteers, COPD and idiopathic pulmonary fibrosis patients. Respiration 2013;85(4):319325 .

2. Chatila W, Nugent T, Vance G, Gaughan J, Criner GJ. The effects of high-flow vs low-flow oxygen on exercise in advanced obstructive airways disease. Chest 2004;126(4):1108-1115.

3. Ritchie JE, Williams AB, Gerard C, Hockey H. Evaluation of a humidified nasal high-flow oxygen system, using oxygraphy, capnography and measurement of upper airway pressures. Anaesth Intensive Care 2011;39(6):1103-1110.

4. Corley A, Caruana LR, Barnett AG, Tronstad O, Fraser JF. Oxygen delivery through high-flow nasal cannulae increase end-expiratory lung volume and reduce respiratory rate in post-cardiac surgical patients. Br J Anaesth 2011;107(6):998-1004.

5. Itagaki T, Okuda N, Tsunano Y, Kohata H, Nakataki E, Onodera M, et al. Effect of high-flow nasal cannula on thoraco-abdominal synchrony in adult critically ill patients. Respir Care 2014;59(1):70-74.

6. Sztrymf B, Messika J, Bertrand F, Hurel D, Leon R, Dreyfuss D, Ricard JD. Beneficial effects of humidified high flow nasal oxygen in critical care patients: a prospective pilot study. Intensive Care Med 2011;37(11):1780-1786.

7. Parke RL, McGuinness SP, Eccleston ML. A preliminary randomized controlled trial to assess effectiveness of nasal high-flow oxygen in intensive care patients. Respir Care 2011;56(3):265-270.

8. Maggiore SM, Idone FA, Vaschetto R, Festa R, Cataldo A, Antonicelli $\mathrm{F}$, et al. Nasal high-flow versus Venturi mask oxygen therapy after extubation. Am J Respir Crit Care Med 2014;190(3):282-288.

9. Rello J, Pérez M, Roca O, Poulakou G, Souto J, Laborda C, et al. High-flow nasal therapy in adults with severe acute respiratory infection. A cohort study in patients with 2009 influenza A/H1N1v. J Crit Care 2012;27(5):434-439.

10. Clinical effect of the association of noninvasive ventilation and high flow nasal oxygen therapy in resuscitation of patients with acute lung injury (FLORALI Study). http://clinicaltrials.gov/ct2/show/record/ NCT01320384. Accessed November 19, 2014.

11. Futier E, Paugam-Burtz C, Constantin JM, Pereira B, Jaber S. The OPERA trial-comparison of early nasal high flow oxygen therapy with standard care for prevention of postoperative hypoxemia after abdominal surgery: study protocol for multicenter randomized controlled trial. Trials 2013;14:341.

12. Messika J, Ben Ahmed K, Gaudry S, Miguel-Montanes R, Rafat C, Sztrymf B, et al. Use of high-flow nasal cannula oxygen therapy in subjects with ARDS: a 1-year observational study. Respir Care 2015; 60(2):162-169. 